\title{
Effects of Geminal Methyl Groups on the Tunnelling Rates in the Ring Opening of Cyclopropylcarbinyl Radical at Cryogenic Temperature ${ }^{\dagger, \#}$
}

\author{
Xue Zhang, ${ }^{\ddagger}$ David A. Hrovat, ${ }^{\ddagger}$ Ayan Datta, ${ }^{\neq}$and Weston Thatcher Borden* $*$ \\ Received (in $X X X, X X X) X t h X X X X X X X X X 200 X$, Accepted Xth $X X X X X X X X X 200 X$ \\ ${ }_{5}$ First published on the web Xth $X X X X X X X X X 200 X$ \\ DOI: $10.1039 / b 000000 x$
}

CVT + SCT calculations on the rate of tunnelling at $20 \mathrm{~K}$ in the ring opening of cyclopropylcarbinyl radical, substituted with geminal methyl groups at a ring carbon (1b), have been ${ }_{10}$ performed. The calculations predict that, contrary to expectations based on the effect of mass on the rate of tunnelling, the geminal methyl substituents in $1 \mathrm{~b}$ should make the rate of ring opening to 1,1-dimethyl-3-butenyl radical (2b) $10^{4}$ times faster than the rate of ring opening of unsubstituted 15 cyclopropylcarbinyl radical (1a) to 3-butenyl radical (2a) and almost $10^{6}$ times faster than the rate of ring opening of $1 \mathrm{~b}$ to 2,2dimethyl-3-butenyl radical (2c). The reasons for these unexpected findings are discussed.

The ring opening of cyclopropylcabinyl radical (1a) to 320 butenyl radical (2a), shown in Scheme 1, has been extensively investigated. ${ }^{1}$ The extreme rapidity of this reaction has resulted in its widespread use as a "radical clock" for timing the rates of other free radical reactions. ${ }^{2}$

Professor Athel Beckwith made many important contributions 25 to the study of this ring opening reaction, ${ }^{3}$ including measuring the effects of substituents on it. For example, in 1989 Newcomb $^{4}$ and Beckwith ${ }^{5}$ published back-to-back papers on the ring opening of 2,2-dimethylcyclopropylcarbinyl radical (1b). Although the tertiary radical center in $\mathbf{2 b}$ makes it by far the 30 thermodynamically preferred product, ring opening of $\mathbf{1 b}$ to $\mathbf{2} \mathbf{b}$ is only favored kinetically over ring opening to $\mathbf{2 c}$ by a factor of about 6.5 at both $25^{\circ 4}$ and $60^{\circ} .5$ The temperature dependence of the ratio of $\mathbf{2 b} / \mathbf{2 c}$ is apparently small, and $1 \mathrm{kcal} / \mathrm{mol}$ probably is an upper limit on the difference between the $E_{\mathrm{a}}$ values for these 35 two reactions. The results of several different types of ab initio calculations, performed by Schlegel and Newcomb, ${ }^{6}$ also give values of slightly less than $1 \mathrm{kcal} / \mathrm{mol}$ for the difference between the barrier heights for ring opening of $\mathbf{1 b}$ to $\mathbf{2 b}$ and $\mathbf{2 c}$.

40 Scheme 1

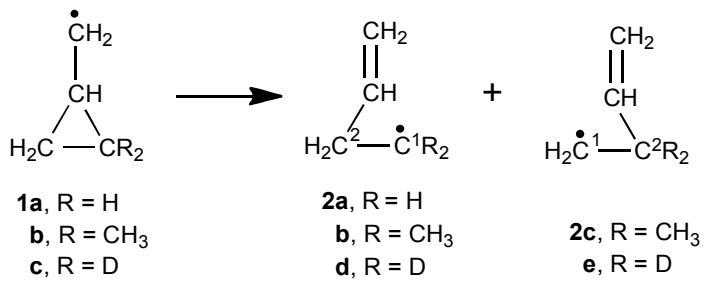

The rate constants for the ring opening of the unsubstituted 45 radical (1a) have been measured at temperatures as low as $128 \mathrm{~K}^{7}$ and as high as $395 \mathrm{~K}^{8}$ An Arrhenius plot over this very wide temperature range is reasonably linear and gives $E_{\mathrm{a}}=7.05$ $\mathrm{kcal} / \mathrm{mol}$ and $\log A=13.15 \mathrm{~s}^{-1}$. 9 The linear Arrhenius plot and the high $A$ factor both suggest that, at least at the high end of this so temperature range, the ring opening of $\mathbf{1 a}$ to $\mathbf{2 a}$ proceeds largely by passage over the reaction barrier, rather than by tunnelling through it.

We have been interested in the possibility that, at cryogenic temperatures, 1a might undergo rapid ring opening by tunnelling, ${ }_{55}$ despite the fact that a $\mathrm{CH}_{2}$ group, rather than a hydrogen atom, would have to tunnel in this reaction. Although not common, there are now several reactions in which experiments have shown that tunnelling by carbon can occur and occur rapidly. ${ }^{10}$

The two requirements for tunnelling by carbon to be rapid are a ${ }_{60}$ reaction barrier that is both low and narrow. ${ }^{10}$ These requirements are met in the ring opening of $\mathbf{1 a}$. Indeed our previous calculations have predicted that, at temperatures up to $20 \mathrm{~K}$, the ring opening of 1a to 2a should occur exclusively by temperature-independent tunnelling from the lowest vibrational 65 level of $1 \mathrm{a}$, with $k=2.22 \times 10^{-2} \mathrm{~s}^{-1}$. 11

Although the rate of ring opening of 1a has not yet been measured at cryogenic temperatures, the intramolecular ${ }^{13} \mathrm{C}$ kinetic isotope effects (KIEs) on this reaction have been determined in solution between $173-253 \mathrm{~K}$ by Gonzalez-James 70 and Singleton. ${ }^{12}$ The KIEs that they measured support the hypothesis that tunnelling plays an increasingly important role in the ring opening of $\mathbf{1 a}$ as the temperature is lowered. The experimental KIEs are fit much better by KIEs, computed with inclusion of small-curvature tunnelling (SCT) corrections, than

75 by KIEs, computed without inclusion of tunnelling. In addition, an Arrhenius plot of the experimental ${ }^{13} \mathrm{C} /{ }^{12} \mathrm{C}$ KIEs is curved. The curvature provides purely experimental evidence, independent of comparisons between computed and measured rate constants, for a prominent role for tunnelling in the ring 80 opening of $\mathbf{1 a}$.

In the ring opening of $1 \mathrm{a},{ }^{13} \mathrm{C}$ tends to become concentrated at $\mathrm{C} 2$ of $2 \mathrm{a},{ }^{12}$ because $\mathrm{C} 1$ undergoes much more motion than $\mathrm{C} 2$ in the ring opening reaction; and the probability of tunnelling is higher for the lighter isotope of carbon $\left({ }^{12} \mathrm{C}\right)$. For the same 85 reason, our SCT calculations predicted that, at $20 \mathrm{~K}$, with geminal deuteria, attached to a ring carbon of $1 \mathbf{c}$, the deuteria will tend to wind up at $\mathrm{C} 2$ (as in $\mathbf{2 e}$ ), rather than at $\mathrm{C} 1$ (as in $\mathbf{2 d}$ ). ${ }^{13}$ Therefore, it is easy to guess that the regiochemistry of the ring opening of $\mathbf{1 b}$, found around room temperature by Newcomb and 90 Beckwith, will be reversed at $20 \mathrm{~K}$ by tunnelling and that $2 \mathbf{c}$, not $\mathbf{2 b}$, will be the major product.

We have tested this prediction by carrying out tunnelling calculations on the ring opening of $\mathbf{1 b}$ at $20 \mathrm{~K}$. Our results show that this naive prediction is completely wrong. Our calculations 95 on the ring opening of $\mathbf{1 b}$, by tunnelling from the lowest vibrational level, actually give a ratio of $\mathbf{2 b} / \mathbf{2} \mathbf{c}$ that is computed to be many orders of magnitude larger at $20 \mathrm{~K}$ than the ratio of ca. 6.5, found by the experiments of Newcomb and Beckwith around room temperature. ${ }^{4,5}$ 
In carrying out tunnelling calculations on the ring opening of 1b, we employed computational methodology similar to that we used in performing tunnelling calculations on the ring opening of 1a. ${ }^{11,12,13}$ Unrestricted electronic structure calculations were 5 carried out with the B3LYP ${ }^{14}$ functional and the $6-31+G(d, p)$ basis set. ${ }^{15}$ Canonical variational transition state theory $(\mathrm{CVT})^{16}$ was used to locate the transition structure (TS) for the ring opening of $\mathbf{1}$ to $\mathbf{2}$. Quantum effects on the reaction dynamics were computed semiclassically, using the small-curvature tunnelling 10 (SCT) approximation. ${ }^{17}$ The direct dynamics calculations were carried out with GAUSSRATE ${ }^{18}$ as the interface between Gaussian $03^{19}$ and POLYRATE. ${ }^{20}$

The UB3LYP/6-31+G(d,p) and the experimental activation energies for the ring opening of unsubstituted cyclopropyl15 carbinyl radical (1a) and the 2,2-dimethyl derivative (1b) are given in Table 1. The UB3LYP activation energies are in reasonable agreement with the experimental values, except that the calculated $E_{\mathrm{a}}$ for ring opening of $\mathbf{1 b}$ to $\mathbf{2} \mathbf{b}$ appears to be ca. 1 $\mathrm{kcal} / \mathrm{mol}$ too low. Therefore, since the calculated difference in $E_{\mathrm{a}}$ 20 values for formation of $\mathbf{2 b}$ and $\mathbf{2 c}$ is a little too high, the calculated product ratio of $\mathbf{2 b}$ to $\mathbf{2 c}$ of 25.4 at $300 \mathrm{~K}$ is about a factor of four larger than the observed value. ${ }^{4,5}$

Table 1. Enthalpy differences ${ }^{\mathrm{a}}$ at $300 \mathrm{~K}$, computed by B3LYP/6$31+\mathrm{G}(\mathrm{d}, \mathrm{p})$ for the ring opening of cyclopropylcarbinyl radicals $\mathbf{1 a}$ 25 and $\mathbf{1 b}$ and the $E_{\mathrm{a}}$ values that have been measured.

\begin{tabular}{cccc}
\hline & $\mathbf{1 a} \rightarrow \mathbf{2 a}$ & $\mathbf{1 b} \rightarrow \mathbf{2 b}$ & $\mathbf{1 b} \rightarrow \mathbf{2 c}$ \\
\hline$\Delta H^{\text {calc }}$ & -3.4 & -7.0 & -0.1 \\
$E_{\mathrm{a}}{ }^{\text {alc }}$ & $7.3^{\mathrm{b}}$ & 5.0 & 6.7 \\
$E_{\mathrm{a}}{ }^{\exp }$ & $7.05^{\mathrm{c}}$ & $6.1^{\mathrm{d}}$ & $7.2^{\mathrm{d}}$ \\
\hline
\end{tabular}

${ }^{\mathrm{a}}$ Values in $\mathrm{kcal} / \mathrm{mol} .{ }^{\mathrm{b}} 7.6 \mathrm{kcal} / \mathrm{mol}$ with the $6-31 \mathrm{G} *$ basis set (ref. 11). ${ }^{\mathrm{c}}$ Ref. $9 .{ }^{\mathrm{d}}$ Ref. 6

The results of our CVT + SCT calculations, comparing the rates of ring opening of $\mathbf{1 a}$ and $\mathbf{1 b}$ at $20 \mathrm{~K}$, are given in Table 2. Tunnelling rates are expected to decrease exponentially with the 30 square root of the effective tunnelling mass. ${ }^{21}$ Therefore, at first glance, it is not surprising that the geminal methyl groups in $\mathbf{1 b}$ are computed to slow the rate of formation of ring-opened product $\mathbf{2 c}$, in Scheme 1 by a factor of 39.1, relative to the rate of formation of $\mathbf{2 a}$ from $1 \mathbf{a}$.

Table 2. $\mathrm{CVT}+\mathrm{SCT}$ rate ratios ${ }^{\mathrm{a}}$ calculated for ring opening of 1a-c to 2 a-e at $20 \mathrm{~K}$.

\begin{tabular}{ccc}
\hline $\begin{array}{c}\text { Substituted C } \\
\text { in product 2 }\end{array}$ & $k(\mathbf{1 a}) / 2 k(\mathbf{1 b})$ & $k(\mathbf{1 a}) / 2 k(\mathbf{1 c})$ \\
\hline $\mathrm{C}^{1}$ & $5.04 \mathrm{E}-05$ & $6.47^{\mathrm{b}}$ \\
$\mathrm{C}^{2}$ & 39.1 & $0.85^{\mathrm{b}}$ \\
Ratio C $^{1} / \mathrm{C}^{2}$ & $7.76 \mathrm{E}+05^{\mathrm{c}}$ & $0.13^{\mathrm{b}, \mathrm{d}}$ \\
\hline
\end{tabular}

${ }^{a}$ The calculated rates for ring opening of $1 \mathrm{a}$ have been divided by 2 , in order to eliminate the statistical factor that arises from the presence of two equivalent $\mathrm{CH}_{2}$ 40 groups in 1a. ${ }^{\mathrm{b}}$ Ref. $13 .{ }^{\mathrm{c}}$ Predicted ratio of methyl groups at $\mathrm{C}^{\mathrm{l}}(\mathbf{2 b})$ to methyl groups at $C^{2}(\mathbf{2 c})$ in the ring opening of $\mathbf{1 b}$. ${ }^{\mathrm{d}}$ Predicted ratio of $\mathrm{D}_{2}$ at $\mathrm{C}^{1}(\mathbf{2 d})$ to $\mathrm{D}_{2}$ at $\mathrm{C}^{2}$ (2e) in the ring opening of $\mathbf{1 c}$

Also given in Table 2 are the $\mathrm{H} / \mathrm{D}_{2}$ KIEs that we previously ${ }_{45}$ calculated for the ring opening of $\mathbf{1 c} .{ }^{13}$ It should be noted that the geminal deuteria in $\mathbf{1 c}$ are not calculated to retard the rate of ring opening to $2 \mathrm{e}$; in fact, they are actually predicted to accelerate it by a factor of $1 / 0.85=1.2$, relative to the rate of ring opening of 1a to 2a. Thus, the question arises, if geminal deuteria make the 50 rate of ring opening of $\mathbf{1 c}$ to $2 \mathrm{e}$ slightly faster than the rate of ring opening of 1a to 2a, why do geminal methyl groups retard the rate of ring opening of $\mathbf{1 b}$ to $\mathbf{2} \mathbf{c}$ by a factor of 39.1 , relative to the rate of ring opening of $\mathbf{1 a}$ to $\mathbf{2 a}$ ?
Table 2 also shows that geminal deuteria are calculated to 55 make the rate of ring opening of $\mathbf{1 c}$ to $\mathbf{2 d}$ a factor of 6.47 slower than the rate of ring opening of $\mathbf{1 a}$ to $\mathbf{2 a}$. However, in stark contrast, the geminal methyl groups in $\mathbf{1 b}$ are actually predicted to accelerate the rate of ring opening to $2 \mathrm{~b}$ by a factor of $1 /(2 \mathrm{x}$ $5.04 \times 10^{-5}$ ) $\approx 10,000$.

$60 \quad$ The explanation of both of these unexpected predictions about the ring opening of $\mathbf{1 b}$ to $\mathbf{2} \mathbf{b}$ and $\mathbf{2 c}$ must be that more than just the mass of the methyl groups affects the rate of tunnelling in the ring opening of $\mathbf{1 b}$. For example, as shown in Table 1 the geminal methyl groups make the calculated exothermicity of the ring 65 opening of $\mathbf{1 b}$ to $\mathbf{2 b}$ larger than that of $\mathbf{1 a}$ to $\mathbf{2 a}$ by $3.6 \mathrm{kcal} / \mathrm{mol}$. Probably as a direct result of this increased exothermicity, the methyl groups make the calculated barrier for $\mathbf{1 b} \rightarrow \mathbf{2 b} 2.3$ $\mathrm{kcal} / \mathrm{mol}$ lower than that for 1a $\rightarrow \mathbf{2 a}$. The methyl groups at $\mathrm{C} 1$ of 2b obviously stabilize the radical center at this carbon; and, to a 70 lesser extent, they stabilize the incipient radical center at this carbon in the transition structure for ring opening of $\mathbf{1 b}$.

The lower barrier to ring opening of $\mathbf{1 b}$ to $\mathbf{2} \mathbf{b}$, compared to that for ring opening of $\mathbf{1 a}$ to $\mathbf{2 a}$, makes tunnelling through the former barrier more probable than tunnelling through the latter. ${ }^{21}$ 75 Therefore, the effect of the methyl groups on reducing the barrier height for ring opening of $\mathbf{1 b}$ to $\mathbf{2 b}$ will, in contrast to the effect of the greater mass of the methyl groups, tend to increase the rate of tunnelling.

In addition, because the ring opening of $\mathbf{1 b}$ to $\mathbf{2} \mathbf{b}$ is more 80 exothermic than the ring opening of $\mathbf{1 a}$ to $\mathbf{2 a}$, according to Hammond's postulate, ${ }^{22} \mathbf{1} \mathbf{1 b} \rightarrow \mathbf{2} \mathbf{b}$ is likely to have an earlier transition structure than $\mathbf{1 a} \rightarrow \mathbf{2 a}$. An earlier transition structure for $\mathbf{1 b} \rightarrow \mathbf{2} \mathbf{b}$ implies that this ring opening reaction should have a narrower barrier than $\mathbf{1 a} \rightarrow \mathbf{2 a} .^{22 b}$ In fact, as shown in Figure 1, 85 our POLYRATE calculations find that the barrier width in the ring opening of $\mathbf{1 b}$ to $\mathbf{2 b}$ is $0.54 \AA$, which is $21 \%$ smaller than the barrier width of $0.68 \AA^{23}$ in the ring opening of $\mathbf{1 a}$ to $\mathbf{2 a}$.

The probability of tunnelling increases exponentially as the reaction barrier width and height are decreased..$^{21,24}$ Therefore, the $9021 \%$ narrower barrier width and the $32 \%$ lower barrier height for $\mathbf{1 b} \rightarrow \mathbf{2 b}$ than for $\mathbf{1 a} \rightarrow \mathbf{2 a}$ both tend to make ring opening of $\mathbf{1 b}$ to $\mathbf{2 b}$ much faster than the ring opening of $\mathbf{1 a}$ to $\mathbf{2 a}$. According to the results in Table 2, the acceleration of the rate of tunnelling, due to the lower and thinner barrier for $\mathbf{1 b} \rightarrow \mathbf{2} \mathbf{b}$ than for $\mathbf{1 a}$

${ }_{95} \rightarrow \mathbf{2 a}$, more than overcomes the larger effective tunnelling mass in the ring opening of $\mathbf{1 b}$ to $\mathbf{2 b}$.

Do barrier height and/or barrier width also play a role in retarding the rate of tunnelling in the ring opening of $\mathbf{1 b}$ to $\mathbf{2 c}$ ? As already noted, the geminal deuteria in 1c are calculated 100 actually to accelerate the rate of ring opening to $2 \mathrm{e}^{.13}$ so it is hard to see why the mass of the methyl groups should serve to retard the rate of ring opening of $\mathbf{1 b}$ to $\mathbf{2 c}$. Moreover, as shown in Table 1 , the barrier for ring opening of $\mathbf{1 b}$ to $\mathbf{2 c}$ is actually calculated to be $0.6 \mathrm{kcal} / \mathrm{mol}$ lower than that for ring opening of $\mathbf{1 a}$ to $\mathbf{2 a}$. 105 Therefore, a higher barrier cannot be the cause of the finding that $\mathbf{1 b} \rightarrow \mathbf{2 c}$ is calculated to be 39.1 times slower than $\mathbf{1 a} \rightarrow \mathbf{2 a}$. Consequently, by process of elimination, the factor that is responsible for the slower rate of ring opening of $\mathbf{1 b}$ to $\mathbf{2 c}$, relative to $\mathbf{1 a} \rightarrow \mathbf{2 a}$, must be a wider barrier for the former 10 reaction.

As noted above, Hammond's postulate leads to the expectation that the less exothermic of two closely related reactions should have the wider barrier. ${ }^{22 b}$ As shown in Table 1, the ring opening of $\mathbf{1 b}$ to $\mathbf{2 c}$ is approximately thermoneutral; whereas, the ring 15 opening of $\mathbf{1 a}$ to $\mathbf{2 a}$ is exothermic by $3.4 \mathrm{kcal} / \mathrm{mol}$. Therefore, $\mathbf{1 b}$ $\rightarrow \mathbf{2 c}$ is likely to have a wider barrier than $\mathbf{1 a} \rightarrow \mathbf{2 a}$. In fact, as shown in Figure 1, our POLYRATE calculations find that the width of the barrier for ring opening of $\mathbf{1 b}$ to $\mathbf{2} \mathbf{c}$ is $0.83 \AA$, which 
is $0.15 \AA$ wider than the barrier in the ring opening of $\mathbf{1 a}$ to $2 \mathbf{a}^{24}$ The wider the barrier, the lower the rate of tunnelling; so the wider barrier to ring opening in $\mathbf{1 b} \rightarrow \mathbf{2} \mathbf{c}$ does, indeed, appear to be the reason that the geminal methyl groups retard the rate of 5 this reaction, relative to the ring opening of $1 \mathbf{a} \rightarrow \mathbf{2 a}$.

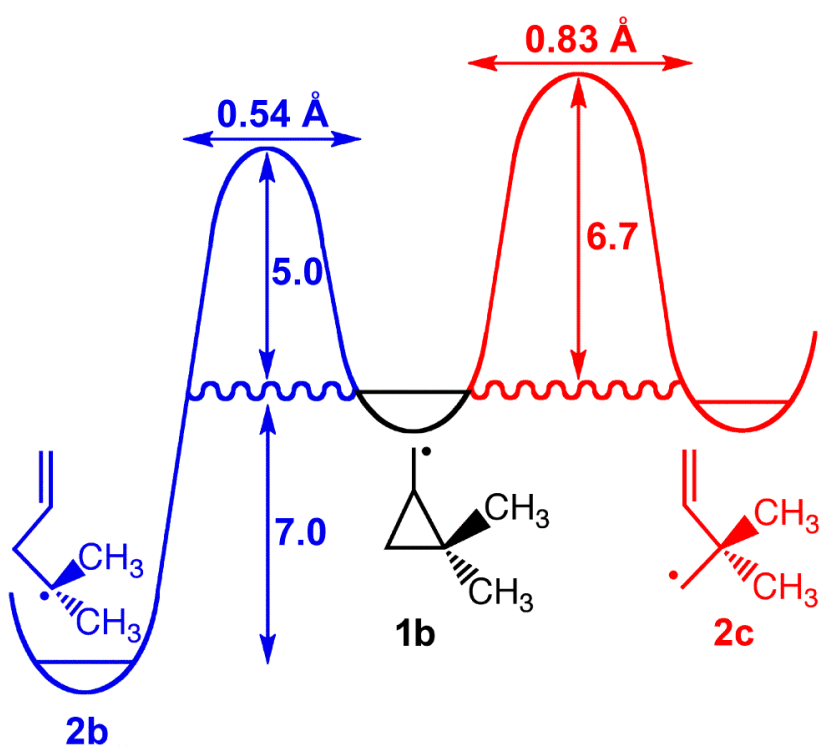

Figure 1. Schematic depiction of the B3LYP/6-31+G(d,p) 10 enthalpy changes for ring opening of $\mathbf{1 b}$ to $\mathbf{2 b}$ and $\mathbf{2 c}$ at $300 \mathrm{~K}$. $\Delta H$ and $E_{\mathrm{a}}$ values are given in $\mathrm{kcal} / \mathrm{mol}$. The enthalpy difference between $\mathbf{2 c}$ and $\mathbf{1 b}$ is calculated to be $\Delta H=-0.1 \mathrm{kcal} / \mathrm{mol}$. The distances given are the calculated barrier widths, using the lengths of the scissile bonds as the reaction coordinates.

15

The combination of the calculated effects of the geminal methyl groups in $\mathbf{1 b}$ on enhancing the rate of ring opening to $\mathbf{2 b}$ and on retarding the rate of ring opening to $2 \mathrm{c}$ leads to the prediction in Table 2 that, at $20 \mathrm{~K}$, tunnelling will give a ratio of geminal methyl 20 groups at $\mathrm{C} 1$ and $\mathrm{C} 2$ of $\mathbf{2 b} / \mathbf{2} \mathbf{c}=7.76 \times 10^{5}$. This ratio of the tunnelling rates for formation of these two products from $1 \mathbf{b}$ at $20 \mathrm{~K}$ is $1.2 \times 10^{5}$ higher than the experimental ratio of $2 \mathbf{b} / \mathbf{2 c}=6.5$ at temperatures between 300 and $360 \mathrm{~K}$, where most of the ring opening reaction of $\mathbf{1 b}$ occurs by passage over the reaction barrier, 25 rather than tunnelling through it.

Table 1 shows that our B3LYP/6-31+G(d,p) calculations overestimate the difference between the barrier heights for formation of $\mathbf{2 b}$ and $\mathbf{2 c}$ from $\mathbf{1 b}$, but by less than $1 \mathrm{kcal} / \mathrm{mol}$. Therefore, the calculated ratio of $\approx 10^{6}$, favoring formation of $2 \mathbf{b}$ over $2 \mathbf{c}$ by 30 tunnelling at $20 \mathrm{~K}$, is large enough to lead us to be confident in making the following prediction: Experiments performed at $20 \mathrm{~K}$ would, in fact, find the ratio of $\mathbf{2 b}$ to $\mathbf{2} \mathbf{c}$ to be many orders of magnitude larger than the ratio of 6.5 , measured at much higher temperatures by Newcomb ${ }^{4}$ and by Beckwith. ${ }^{5}$

\section{${ }_{35}$ Acknowledgements}

We thank the National Science Foundation and the Robert A Welch Foundation for their support through, respectively, Grants CHE-0910527 and B-0027.

\section{Notes and references}

${ }^{\ddagger}$ Department of Chemistry and Center for Advanced Scientific

${ }_{45}$ Computing and Modeling, University of North Texas, 1155 Union

Circle \#305070, Denton, TX 76203-5017, USA

Fax: +01-940-565-4460; Tel: +01-940-565-3658;

E-mail:borden@unt.edu

${ }^{7}$ Present address: School of Chemistry, Indian Institute of Science ${ }_{50}$ Education and Research Thiruvananthapuram, CET Campus, 6

Thiruvanantha-puram-695016, Kerala, India

'Electronic Supplementary Information (ESI) available: [The optimized B3LYP/6-31+G(d,p) geometries, energies, thermal corrections, and harmonic frequencies for $\mathbf{1 a}, \mathbf{1 b}$ and $\mathbf{2 a}, \mathbf{2 b}, \mathbf{2 c}$ and the transition

55 structures connecting them, and the CVT and CVT + SCT rate constants for these reactions. (10 pages)]. See DOI: 10.1039/b000000x/

\# This Communication is dedicated to the memory of Professsor Athel Beckwith.

601 Review: D. C. Nonhebel, Chem. Soc. Rev. 1993, 347.

2 D. Griller and, K. U. Ingold, Acc. Chem. Res. 1980, $13,317$.

3 See, for example, (a) A. Effio, D. Griller, K. U. Ingold, A. L. J. Beckwith, and A. K. Serelis, J. Am. Chem. Soc. 1980, 102, 1734. (b) A. L. J. Beckwith, Beckwith, V. W. Bowry, and K. U. Ingold, J. Am. Chem. Soc. 1992, 114, 4983. (c) A. L. J. Beckwith and V. W. Bowry, J. Am. Chem. Soc. 1994, 116, 2710 .

4 M. Newcomb, A. G. Glenn, and W. G. Williams, J. Org. Chem. 1989, 54, 2675.

705 A. L. J. Beckwith, Beckwith and V. W. Bowry, J. Org. Chem. $1989, \mathbf{5 4}, 2681$.

6 F. N. Martinez, H. B. Schlegel, and M. Newcomb, J. Org. Chem. 1996, 61, 8547.

7 B. Maillard, D. Forrest, and K. U. Ingold. J. Am. Chem. Soc. 1976, 98, 7024.

8 A. L. J. Beckwith, V. W. Bowry, and G. Moad, G. J. Org. Chem. 1988, 53, 1632.

9 M. Newcomb, and A. G. Glenn, J. Am. Chem. Soc. 1989, 111, 275.

8010 R. S. Sheridan in Reviews in Reactive Intermediate Chemistry; eds. R. A. Moss, M. S. Platz, M. J. Jones, Jr., John Wiley \& Sons, New York, 2007, 415.

11 A. Datta, D. A. Hrovat, and W. T. Borden, J. Am. Chem. Soc. 2008, 130, 6684.

${ }_{85} 12$ O. M. Gonzalez-James, X. Zhang, D. A. Hrovat, W. T. Borden, and D. A. Singleton, J. Am. Chem. Soc. 2010, 132, 12548.

13 X. Zhang, A. Datta, D. A. Hrovat, and W. T. Borden, J. Am. Chem. Soc. 2009, 131, 16002.

9014 (a) A. D. Becke, J. Chem. Phys. 1993, 98, 5648. (b) C. Lee, W. Yang, and R. G. Parr, Phys Rev. B 1988, 37, 78. (c) B. Miehlich, A. Savin, H. Stoll, and H. Preuss,. Chem. Phys. Lett. 1989, 157, 200. (d) Of the many functionals that we tried, B3LYP gave $E_{\mathrm{a}}$ values for the ring opening of $\mathbf{1 a}$ to $\mathbf{2 a}$ and $\mathbf{1 b}$

95 to $\mathbf{2 b}+\mathbf{2} \mathbf{c}$ that provided the best agreement with the experimental values given in Table 1 .

15 (a) W. J. Hehre, R. Ditchfield and J. A. Pople, J. Chem. Phys. 1972, 56, 2257. (b) P. C. Harihan and J. A. Pople, Mol. Phys. 1974, 27, 209 (c) W. J. Hehre, L. Radom, P. v. R. Schleyer and J. A. Pople, Ab Initio Molecular Orbital Theory; WileyInterscience: New York, 1985, Chapter 6.

16 D. G. Truhlar and B. C. Garrett, Annu. Rev. Phys. Chem. 1984, 35, 159.

17 A. Fernandez-Ramos, B. A.; Ellingson, B. C. Garrett, D. G.

105 Truhlar. in Reviews in Computational Chemistry, 23, eds. K. B. Lipkowitz and T. R. Cundari, Wiley-VCH, Hoboken, NJ, 2007, 125-232. 
18 J. C. Corchado, Y.-Y. Chuang, E. L Coitino, B. A. Ellingson, and D. G. Truhlar, GAUSSRATE-version 9.5; University of Minnesota: Minneapolis, MN.

19 M. J. Frisch, G. W. Trucks, H. B. Schlegel, G. E. Scuseria, M. A. Robb, J. R. Cheeseman, J. A. Montgomery, Jr., T. Vreven, K. N. Kudin, J. C. Burant, J. M. Millam, S. S. Iyengar, J. Tomasi, V. Barone, B. Mennucci, M. Cossi, G. Scalmani, N. Rega, G. A. Petersson, H. Nakatsuji, M. Hada, M. Ehara, K. Toyota, R. Fukuda, J. Hasegawa, M. Ishida, T. Nakajima, Y. Honda, O. Kitao, H. Nakai, M. Klene, X. Li, J. E. Knox, H. P. Hratchian, J. B. Cross, V. Bakken, C. Adamo, J. Jaramillo, R. Gomperts, R. E. Stratmann, O. Yazyev, A. J. Austin, R. Cammi, C. Pomelli, J. W. Ochterski, P. Y. Ayala, K. Morokuma, G. A. Voth, P. Salvador, J. J. Dannenberg, V. G.

15 Zakrzewski, S. Dapprich, A. D. Daniels, M. C. Strain, O. Farkas, D. K. Malick, A. D. Rabuck, K. Raghavachari, J. B. Foresman, J. V. Ortiz, Q. Cui, A. G. Baboul, S. Clifford, J. Cioslowski, B. B. Stefanov, G. Liu, A. Liashenko, P. Piskorz, I. Komaromi, R. L. Martin, D. J. Fox, T. Keith, M. A. Al-

20 Laham, C. Y. Peng, A. Nanayakkara, M. Challacombe, P. M. W. Gill, B. Johnson, W. Chen, M. W. Wong, C. Gonzalez, and J. A. Pople, Gaussian 03, revision E.01; Gaussian, Inc.: Wallingford, CT, 2004.

20 J. C. Corchado, Y.-Y Chuang, P. L. Fast, W.-P Hu, Y.-P Liu,

25 G. C. Lynch, K. A. Nguyen, C. F. Jackels, A. Fernandez Ramos, B. A. Ellingson, B. J. Lynch, V. S. Melissas, J. Villà, I. Rossi, E. L. Coitiño, J. Pu, T. V. Albu, R. Steckler, B. C. Garrett, A. D. Isaacson, and D. G. Truhlar, POLYRATEversion 9.5; University of Minnesota: Minneapolis, MN, 2007.

21 R. P. Bell, The Tunnel Effect in Chemistry, Chapman and Hall, New York, 1980.

22 (a) G. S. Hammond, J. Am. Chem. Soc. 1955, 77, 334. (b) The corollary to Hammond's postulate, that the more exothermic of two reactions should have the narrower barrier, is irrelevant for reactions that occur by passage over energy barriers. However, this corrolary is of critical importance for reactions that occur by tunnelling through energy barriers, especially by tunnelling from the lowest vibrational levels of the reactants.

4023 The barrier width of $0.68 \AA$, calculated with the $6-31+\mathrm{G}(\mathrm{d}, \mathrm{p})$ basis set, is $0.04 \AA$ narrower than the barrier width computed in ref. 11, with the 6-31G(d) basis set.

24 The negative logarithm of the tunnelling probability depends on a product of terms, which involve the square roots of the barrier height and effective tunnelling mass; but the product is linear in the barrier width. ${ }^{21}$ Therefore, a factor of two decrease in barrier width increases exponentially the probability of tunnelling by the same amount as a factor of four decrease in barrier height or in effective tunnelling mass. 